\title{
O LIRISMO DE CAIO VALÉRIO CATULO. UMA LEITURA DE SEU POEMA SOBRE UM BARCO (CARM. IV)
}

Maria da Glória Novak*

RESUMO: Catulo, o primeiro grande lírico da língua latina, poeta nouus, na expressão de Cícero, e herdeiro da poesia de Alexandria, conserva a sua independência em relação ao alexandrinismo e parece que supera os seus modelos: o seu gênio romano ilumina a sua poesia. Mesmo o poema sobre o barco, por exemplo, é novo sob a arte de Catulo e é indubitavelmente italiano. E revela a técnica do Poeta, e um sentimento de cores bem marcadas: o poema sobre o barco, aparentemente muito simples, tem algo de muito profundo.

Palavras-chave: Lirismo, vida, romanidade, raça.

Pouco se sabe sobre a vida de Catulo. Pode-se ter como certo que o local de seu nascimento é Verona, que fica na Gália Transpadana, pois foi sempre chamado Veronense. Teria vivido de $87 / 82$ a 54/52 a.C., ou seja, na época de César, de Cícero, de Lucrécio: época de um dos maiores documentos poéticos do Ocidente, época do apogeu da prosa latina, e das mais conturbadas da política romana.

Mas, ao contrário do que se poderia pensar, não se encontra em Catulo uma poesia política, mas tão-somente invectivas pessoais, a Pompeu, por exemplo, a César, a Mamurra ${ }^{1}$

Não sabemos como ou quando chegou a Roma. Parece claro que freqüentou a alta sociedade intelectual romana (cf. 68,34 ), como se pode depreender dos nomes dos destinatários de seus poemas e de sua amizade a Cornélio Nepos, a quem dedica o seu livro, e que também o cita em sua

* Departamento de Letras Clássicas e Vernáculas da FFLCH/USP.

1 Cf. 29; 57 e 113. Mamurra era o principal engenheiro de César na Gália, onde enrıqueceu; foi invectivado por Catulo e "glosado" por Horácı. 

um barco (Carm. iv). Lingua e Literatura, n. 22, p. 137-153, 1996.

obra $^{2}$. Iqualmente sabemos que acompanhou Caio Mêmio à Bitínia, de 57 a 56 (cf. 10 e 28).

Onde estudou não sabemos ao certo. Pode ter sido aluno do gramático e poeta Valério Cato, "fazedor de poetas", igualmente originário da Gália, e a quem alguns estudiosos atribuem grande influência no desenvolvimento da poesia nova em Roma.

O que vem a ser essa poesia nova?

- Catulo pertence a um período de transição entre o antigo e o moderno. De um lado, Lucrécio e o De rerum natura, de linguagem arcaizante, inspirada em Ênio: tradicional e clássico. De outro os poetae noui (como diz Cícero), entre os quais Hélvio Cina, que escreveu um poemeto sobre o mito de Mirra e Adônis, poemeto para o qual Catulo prognosticou a imortalidade, mas do qual só nos restam três versos; Licínio Calvo, que o Veronense lembra no poema $53 \mathrm{e}$, adiante, consola pela perda da esposa, e que teria escrito um poemeto a Ion, filho de Creúsa e Apolo; e, naturalmente, o próprio Caio Valério Catulo.

Esses poetas são, como diz Fordyce (1973, xix), os que rompem com a tradição da poesia latina e lhe dão "estilo e espírito novos, individuais, subjetivos e românticos, e novos padrões de técnica". Desprezados por Cícero, esses poetas se sabem novos e querem sê-lo. O seu credo é a arte pela arte (id., ibid.). E estão ligados a uma Escola que se conhece como Alexandrina. Sobre o alexandrinismo, lembremos ainda Fordyce: a poesia de Alexandria, chegando ao fim de longa história poética, era "uma literatura de exaustão, procurando novidade na forma e no conteúdo porque, segundo afirmara Calímaco de Cirene, "tudo já havia sido feito" (ibid.). Caracterizam-na a erudição e o prazer estético. Os dois gêneros mais em voga são, então, a elegia e o conto épico; além desses, encontram-se o epigrama, o idílio e o mimo. Os maiores nomes da poesia de Alexandria, ao lado de Calímaco, são Filetas de Cós e seus poemas de amor, Apolônio de Rodes e seu poema épico sobre os Argonautas, Teócrito de Siracusa (Cós e Alexandria) com seus idílios, e Arato de Solos, autor dos Fenômenos.

Paradoxalmente, podemos dizer que os poetas novos se opõem aos alexandrinos porque, embora neles se inspirem, são antes de tudo romanos, e o seu gênio romano ilumina a sua poesia. Os estudiosos são quase unânimes em afirmar que esses poetas não apenas escreviam sobre as suas pai-

2 Cf. 1, Nepos; 10, Varo; 14 e 50 e 96, Calvo; 38, Cornificio; 49, Cícero; 61, Torquato; 65, Ortalo; 95, Cina. Cf. também C.N., Att., 12, 4. 
xões mas sentiam-nas ( $\mathrm{sic}$ ), e que a sua poesia não brotava da inteligência mas da sensibilidade, respirando paixão e ardor de vida. E aí residiria a grande diferença entre os verdadeiros alexandrinos e os alexandrinos romanos. Catulo será provavelmente o maior destes e talvez o maior entre todos os alexandrinos. É o mais ardente poeta do eu das literaturas clássicas; e a sua poesia, embora tecnicamente perfeita, é um grito apaixonado e genial, que brota da mais profunda alma romana - e, no entanto, é moderno.

Ao lado de poemas curtos em metro variado, principalmente jambos (os cinqüenta e nove primeiros da coleção, assim como a temos) deixou-nos epigramas em dísticos elegíacos, os quarenta e nove últimos, poemas curtos, à exceção do que tem o número 76 ( Si qua recordanti), que tem vinte e seis versos, e nove poemas de inspiração erudita e bem alexandrina, em geral longos (variando de quarenta a quatrocentos e oito versos). Entre estes, encontram-se: um que chora a morte do irmão (65), outro (66) que é a tradução da "cabeleira de Berenice", de Calímaco, e também o epitalâmio de Tétis e Peleu (64), o mais longo.

Lafaye (1966, xvii) discute essa divisão tradicional e talvez incluisse entre os primeiros (1-60) os poemas 61 (a Torquato) e 62 (também de himeneu, Vesper adest), pelas suas características líricas. Seja como for, não sabemos em que ordem os teria publicado o Poeta, ou como os teria agrupado. Mesmo nos poemas 61 a 68b, e mesmo em Tétis e Peleu (64), seu melhor modelo alexandrino, Catulo mostra sua independência com relação ao alexandrinismo. Sente-se perpassarem na sua obra ecos também de Homero, de Arquíloco, de Píndaro, e dos líricos de Lesbos, Alceu e Safo. E a sua poesia, porque sofre o influxo do gênio transpadano e do seu próprio gênio, tem uma força que a poesia de Filetas e Calímaco, por exemplo, talvez não tenha. Mesmo os poemas sobre o barco (4), o pardal (3: Lugete o Veneres Cupidinesque) e outros que têm modelos gregos, são novos sob a arte de Catulo e são indubitavelmente italianos.

O Poeta é principalmente conhecido pelo seu romance em versos, história de amor e ódio, esperança e desespero, os poemas a Lésbia e sobre Lésbia, e $a$ e contra possíveis rivais do amor. É tão convincente que, durante séculos, ninguém terá pensado em discutir a existência real do objeto da paixão.

É bem verdade que, no século II da nossa era, Apuleio ( $A$ pol. 10) deu a Lésbia o nome de Clódia. Desde então, tentou-se combinar esse dado com alguns poemas (notadamente 77 e 79), para ver nessa Clódia citada por Apuleio a esposa de Metelo, governador da Gália Cisalpina. No poema 77, 

um barco (Carm. iv). Língua e Literatura, n. 22, p. 137-153, 1996.

Catulo interpela um Rufo (que seria Célio Rufo), seu sucessor no coração de Lésbia. No 79, um Lésbio Pulcher, que não seria outro senão Clódio Pulcher, irmão de Clódia, que, a crermos Cícero (Pro Sest. 16), teria com ela um romance. E a identificação atravessou os séculos. Na edição de 1966 dos poemas de Catulo pela Société d'Édition "Les Belles Lettres", lê-se ainda o que G. Lafaye escrevera quarenta e três anos antes: que a identidade de Lésbia com Clódia é admitida pela maioria dos críticos literários (p. xii). Identidade que só recentemente foi posta em xeque: Lésbia pode ser uma personagem de ficção. Não teria realmente existido, nem isso tem importância. A personagem tem vida própria.

Horácio, embora desprezasse os poetas novos (Sat. I 10,19), sofreu influência de Catulo. Também Vergílio. E também o pseudovergiliano Catalepton. E Catulo também foi lembrado no século I d.C. pelos dois Plínios, por Quintiliano e Marcial, que sofreu grandemente a sua influência (Costa, 1952, 36). No século II, por Apuleio e Aulo Gélio. Mais tarde, por Isidoro de Sevilha. E não posso impedir-me de lembrar, na esteira de Catulo, os grandes líricos do Brasil, Manuel Bandeira e Carlos Drummond de Andrade.

Resta uma palavra sobre a linguagem de Catulo. Esta é ora popular, chegando às raias do grosseiro nos poemas amorosos e nos epigramas, ora "elegante e requintada" Como diz A. Costa: "às explosões de ódio e de amor, que tanto o aproximam das almas simples e rudes, seguem-se nele manifestações de fino gosto literário" (Costa, 1952, 71).

De fato, na busca da expressividade, o Poeta lança mão de todos os recursos oferecidos pela língua falada e popular. A. Costa faz minucioso exame desses recursos, tanto ao nível da palavra, como ao da frase e dos sons, para concluir que são "indiscutíveis as influências populares no estilo catuliano, nítidas nas composições amorosas e nos epigramas, veladas pela preciosidade alexandrina, nas composições de cunho erudito" (Costa, 1952, 71).

Catulo, um dos maiores poetas de Roma e do Ocidente, Poeta que tem consciência da arte literária e critica mordazmente os maus versos (cf. 36) e os maus discursos (cf. 44), deixou-nos cento e dezessete poemas, num total de pouco mais de dois mil e duzentos e oitenta versos, nos quais celebrou com a mesma intensidade o desprezo, o ódio, a amizade e o amor, e percorreu todas as gamas da comunicação, da mais elevada à mais baixa, e todos os níveis da linguagem, do mais erudito ao mais coloquial, com técnica irrepreensível.

Vejamos o texto. O poema é o de número 4 nas nossas edições, "A chalupa", em latim, Phaselus. Apresento-o no original e em português, para 

um barco (Carm. iv). Lingua e Literatura, n. 22, p. 137-153, 1996.

depois explicar alguns termos e construções. O texto é simples mas belo. A tradução é minha: resisti à tentação de usar a belíssima tradução do Professor Lauro Mistura.

1 Phaselus ille, quem uidetis, hospites,

2 ait fuisse nauium celerrimus,

3 neque ullius natantis impetum trabis

4 nequisse praeterire, siue palmulis

5 opus foret uolare siue linteo.

6 Et hoc negat minacis Adriatici

7 negare litus insulasue Cycladas

8 Rhodumque nobilem horridamque Thraciam

9 Propontida trucemue Ponticum sinum,

10 ubi iste post phaselus antea fuit

11 comata silua: nam Cytorio in iugo

12 loquente saepe sibilum edidit coma.

13 Amastri Pontica et Cytore buxifer,

14 tibi haec fuisse et esse cognitissima

15 ait phaselus; ultima ex origine

16 tuo stetisse dicit in cacumine,

17 tuo imbuisse palmulas in aequore,

18 et inde tot per impotentia freta

19 erum tulisse, laeua siue dextera

20 uocaret aura, siue utrumque Iupiter

21 simul secundus incidisset in pedem;

22 neque ulla uota litoralibus Diis

23 sibi esse facta, cum veniret a marei

24 nouissime hunc ad usque limpidum lacum.

25 Sed haec prius fuere; nunc recondita

26 senet quiete seque dedicat tibi,

27 gemelle Castor et gemelle Castoris.

"A bela chalupa que vedes, romanos, diz que foi o mais veloz dos navios e que era capaz de ultrapassar a impetuosidade de qualquer lenho flutuante, quer lhe fosse necessário voar com os remos ou com a vela.

E diz que não negam isto o litoral do Adriático ameaçador e as ilhas Cíclades e a célebre Rodes e a medonha Propôntida Trácia e o tempestuoso golfo Pôntico, 
onde, mais tarde chalupa, antes ela foi

bosque frondoso: tanto que, no cume do Citoro, muitas vezes sibilou, com a fronde sussurrante.

Amástris do Ponto, Citoro fértil em buxos, que isto foi e é conhecidíssimo de ti

afirma a chalupa: diz que, desde a sua origem última,

se erguia no teu cimo,

embebia os remos em tuas águas

e que daí, por tantos mares tempestuosos, trouxe o seu dono, quer da esquerda ou da direita soprasse a brisa, quer Júpiter ao mesmo tempo

lhe houvesse caido, favorável, nas duas escotas;

e que não fez quaisquer votos aos Deuses

litorâneos embora chegasse do mar,

finalmente, até este límpido lago.

Mas isto foi antes: agora, recolhida, envelhece tranqüilamente e se dedica a ti, gêmeo Cástor, a ti, gêmeo de Cástor."

Faço algumas observações.

Verso 1: Phaselus, que traduzo por "chalupa", é exatamente isso: barco de remos ou de vela. Pode ser masculino ou feminino em latim: nos versos 1, 2 e 10, aparece como masculino: ille quem (v. 1), celerrimus (v. 2), iste (v. 10). Mas, no verso 25, aparece como feminino, recondita. Ille, que traduzo por "bela" tem conotação enaltecedora: aqui não indica distância: a chalupa está perto; tanto que, no mesmo verso 1, diz o Poeta quem uidetis, "que vedes"; e no verso 10, iste, "esse" Traduzo hospites por "romanos"; hospes é aquele que recebe: e a chalupa está em território romano.

Verso 6: no Adriático deságuam o rio Ádige, que banha Verona, e o Pó, que tem um afluente chamado Míncio, que sai do lago Benaco, onde se encontra Sírmio, a península onde Catulo tinha uma casa.

Verso 8: Rodes é nobre pelo Colosso (estátua de Apolo), pelas uvas e pelos navios.

Verso 9: a Propôntida é o atual Mar de Mármara, entre o Mar Egeu e o Ponto Euxino, ou entre os Dardanelos e o Bósforo. É trácia (v. 8) porque banha a Trácia, região a NE da Grécia; e é horrida pela violência das ondas. Ponticus sinus: o Golfo Pôntico, isto é, do Ponto Euxino, "Mar Negro" que banha a Paflagônia e a Bitínia.

Verso 11 : Cytorius, “do Citoro": monte da Paflagônia, ao S do Ponto, a L da Bitínia. 
Verso 13: Amastris: cidade do Ponto, que é o Mar Negro: o pinheiro desceu do Citoro e se fez barco em Amástris. Daí constituir-se Amástris num singular com Citoro (cf. 13-4).

Verso 18: impotens, "sem poder, sem controle, desenfreado" Catulo aplica o adjetivo também a si mesmo e a uma jovem apaixonada (cf. 8,9; $35,12)$. Fretum: braço de mar, caracterizado pela agitação das ondas.

Verso 20: Iupiter: única ocorrência em Catulo de Júpiter por vento.

Versos 20-1: utrumque [...] in pedem: "em uma e outra escota": a vela recebe perpendicularmente o vento e desliza rápido.

Verso 22: litorales Di: Netuno, Portuno, Glauco e, principalmente, os Dióscuros, Cástor e Pólux, filhos de Leda e Tíndaro, e Leda e Júpiter, respectivamente.

Verso 24: limpidus lacus: seria (?) o lago Benaco, onde se encontra Sírmio, a jóia de Catulo (cf. 31)? Fiquemos com a dúvida.

Verso 26: Tibi: singular pelo plural: ou, para o Poeta, Cástor e Pólux são um todo, ou Cástor predomina; por exemplo, o templo dos Dióscuros em Roma é chamado aedes Castoris, "templo de Cástor"

Gostaria de dizer duas palavras sobre a métrica. O poema é em senários jâmbicos, e o jambo consta de uma breve e uma longa. $\mathrm{O}$ senário tem seis pés e seis tempos marcados.

A longa pode ser substituída por duas breves, exceto no último pé, em que pode ser substituída por uma, apenas.

A breve pode ser substituída por uma longa, exceto no último pé.

Conseqüentemente, cada breve acaba podendo ser substituída por duas (exceto a última).

Assim, cada jambo, que na origem consta de uma breve e uma longa, pode apresentar uma dentre seis feições diferentes, embora com algumas restrições.

Em suma, a breve pode ser substituída por ıma longa, e o pé é chamado puro quando não há tal substituição; condensado, quando há. Uma só condensação neste poema: quiete (v. 26). Há também, aqui, duas liberdades poéticas: duas breves que o Autor considera longas: Propontida (v. 9) e impotentia (v. 18).

No senário jâmbico, a cesura é, por via de regra, pentemímere, e isso ocorre em 18 versos deste poema; por exemplo, no verso 1 :

Phaselus ille / quem uidetis, hospites.

Encontra-se também, aqui, a heptemímera, em nove versos. Por exemplo: 
Ub(i) iste post phaselus / antea fuit (v. 10).

Uma das características da poesia catuliana, fartamente exemplificada aqui, é a elisão. Repete-se catorze vezes nestes vinte e sete versos, e o verso 14 conta com duas:

$$
\text { tib(i) haec fuiss(e) et esse / cognitissima. }
$$

Outra característica da arte do Veronense é o encadeamento, de que há vários exemplos neste poema. Tomemos os versos 10 e 11:

ub(i) iste post phaselus antea fuit - comata silua, "onde, mais tarde chalupa, antes ela foi - bosque frondoso"

O ritmo do poema, em senários jâmbicos puros, com tantas elisões e tantos encadeamentos, tem a leveza, a rapidez e a ondulação da própria chalupa. Eu não diria que o metro "é um metro de mar, ou de barco", porque outros poemas em que o Poeta emprega o senário jâmbico puro têm assunto bem diferente (o $29^{\circ}$ e o $52^{\circ}$.):

Quis hoc potest uidere, quis potest pati?

"Quem pode ver isto, quem pode suportar?"

contra Mamurra, Pompeu e César; e

Quid est, Catulle? Quid moraris emori?

"Que é isso Catulo? Por que tardas a morrer?"

contra um Nônio e um Vatínio. Em ambos os poemas (o primeiro com vinte e quatro versos, o segundo com quatro), o Poeta extravasa o seu ódio contra a corrupção dos poderosos e contra o nepotismo. Assim, conquanto bem diversos, os três poemas pedem ritmo apressado. Se nos versos do barco a rapidez e ondulação do ritmo correspondem aos movimentos da chalupa nos mares que percorreu, nos outros correspondem à indignação de Catulo.

Gostaria de dizer algo mais: embora seja muito perigoso "dividir" um poema, eu analisaria este, só para entendê-lo, em três segmentos.

Primeiro segmento, versos 1-5:

Phaselus ille, quem uidetis, hospites, 1 
nequ(e) ullius natantis impetum trabis

nequisse praeterire, siue palmulis

opus foret uolare siue linteo,

"A bela chalupa que vedes, romanos, diz que foi o mais veloz dos navios e que era capaz de ultrapassar a impetuosidade de qualquer lenho flutuante, quer lhe fosse necessário voar com os remos ou com a vela"

Sobressai, quase palpável, o primeiro verso, que se projeta sobre todos os outros, sobre o poema todo:

Phaselus ille quem uidetis,

com um verbo no presente, uidetis, "vedes", que envolve o Poeta, a chalupa e os que podem vê-la. Nós também podemos vê-la ao longo de todo o poema, que é a sua história, a história de sua origem, de suas lutas, vitórias, e de sua velhice.

Nos quatro versos seguintes, a chalupa diz (ait, v. 2) quem ela foi e é: barco de remos e de vela: palmulis (v. 4), linteo (v. 5). Mas não qualquer barco de remos e de vela, senão o mais veloz: nauium celerrimus (v. 2). E o superlativo é reforçado no verso 5, pelo verbo ıolare, "voar"

O verbo ait (do v. 2) tem correspondentes ao longo do poema: negat, "nega" (v. 6), ait, "afirma" (v. 15), dicit, "diz" (v. 16): são todos "verbos de dizer", estão todos no presente e têm todos o mesmo sujeito, phaselus: é o phaselus loquens (e esse aspecto é muito importante, como veremos): é a chalupa falando e dando-nos uma visão de seu passado.

Segundo segmento, versos 6-12:

Et hoc negat minacis Adriatici 6

negare litus insulasue Cycladas $\quad 7$

Rhodumque nobil(em) horridamque Thraciam $\quad 8$

Propontida trucemue Ponticum sinum, $\quad 9$

$u b(i)$ iste, post phaselus, antea fuit $\quad 10$

comata silua: nam Cytori(o) in iugo 11

loquente saepe sibil(um) edidit coma, $\quad 12$

"E diz que não negam isto o litoral

do Adriático ameaçador e as ilhas Cíclades

e a célebre Rodes e a medonha Propôntida

Trácia e o tempestuoso golfo Pôntico, 
onde, mais tarde chalupa, antes ela foi bosque frondoso: tanto que, no cume do Citoro, muitas vezes sibilou, com a fronde sussurrante"

A chalupa invoca o testemunho de quem a conhece: o litoral do Adriático, as Cíclades, Rodes, a Propôntida e o Golfo Pôntico. E não só lhes invoca o testemunho, quase os desafia a desmenti-la: negat eos negare, "nega que eles possam negar", afirma que não negarão. Neste segmento, há várias observações que se podem fazer.

A primeira, sobre os adjetivos minax, "ameaçador" (v. 6), horrida, "medonha" (v. 8), e trux, "tempestuoso" (v. 9), que qualificam não apenas Adriático, Propôntida e Golfo Pôntico mas, também, caracterizam a própria feição da chalupa, que, até o quinto verso, aparece como o mais veloz dos barcos; agora começa a aparecer como brava, audaciosa, talvez. Há nestes quatro versos (6-9) uma sugestão das lutas empreendidas por ela, sintetizadas adiante principalmente na expressão per impotentia freta, "por mares tempestuosos" (v. 18).

A segunda observação diz respeito aos versos 10-2:

ub(i) iste, post phaselus, antea fuit comata silua: nam Cytori(o) in iugo loquente saepe sibil(um) edidit coma, "onde, mais tarde chalupa, antes ela foi bosque frondoso: tanto que, no cume do Citoro, muitas vezes sibilou, com a fronde sussurrante"

Estes versos reportam-se à origem da chalupa e explicam tudo o que foi dito até agora e preparam tudo o que virá a seguir, porque explicam o próprio phaselus: verso 10: $u b i$, "onde"? - No Citoro, às margens do golfo Pôntico. Ora, a chalupa afirma que fora bosque frondoso antes de ser barco: antea fuit comata silua (v. 10-1). E fora um bosque frondoso lá no golfo Pôntico: então ela fora um pinheiro: e ser pinheiro no Ponto é poder ser o mais veloz e o mais bravo dos barcos. Eu diria que esse ubi justifica a personalidade da chalupa: e assim é que explica o que virá depois, também.

A terceira observação recai sobre o termo antea (v. 10). Este antea tem a sua definição cinco versos adiante (v. 15): ultim(a) ex origine: "fora antes bosque frondoso"; não apenas antes de ser barco, mas sempre até ser barco.

A quarta observação focaliza o verso 12: 
loquente saepe sibil(um) edidit coma,

"muitas vezes sibilou, com a fronde sussurrante"

e destaca a expressão loquente coma, concentrando-se principalmente no vocábulo que inicia o verso, loquente, que encerra a magia do poema: o barco fala - phaselus ait (v. 1-2) - e já falava, pela sua folhagem, quando era pinheiro do Ponto. Isto me parece a personificação do barco. Veremos, aliás, que a sua vida é a nossa vida.

Terceiro segmento: versos 13-24. Este, analisado em três partes menores.

Primeira parte: versos 13-7:

$\begin{array}{ll}\text { Amastri Pontic(a) et Cytore buxifer, } & 13 \\ \text { tib(i) haec fuiss(e) et esse cognitissima } & 14 \\ \text { ait phaselus; ultim(a) ex origine } & 15 \\ \text { tuo stetisse dicit in cacumine, } & 16 \\ \text { tu(o) imbuisse palmulas in aequore, } & 17 \\ \text { "Amástris do Ponto, Citoro fértil em buxos, } & \\ \text { que isto foi e é conhecidissimo de ti } & \\ \text { afirma a chalupa: diz que, desde a sua origem última, } & \\ \text { se erguia no teu cimo, } & \\ \text { embebia os remos em tuas águas" } & \end{array}$

Vocativos no verso 13, e afirmações que ligam o passado remoto ao presente: com um encadeamento sugestivo, ligando os versos 13 e 14: cognitissima / ait: "que foi, e é, conhecidíssimo de ti / afirma"

$O$ verso 13 resume-se em um só vocábulo no verso seguinte: $t i b i$, que refere a um tempo Amástris $e$ o Citoro, ligados, aliás, por elisão no verso 133; de fato o Citoro fica na cidade de Amástris. O Poeta invoca-os porque eles existem ainda sabem ainda.

Ao verso 14 cabem algumas observações.

1) Elisão entre tibi e haec: entre Amástris e o Citoro (tibi) e o passado remoto (haec): este haec retoma os versos 10 a 12 :

$\mathrm{ub}(\mathrm{i})$ iste, post phaselus, antea fuit comata silva: nam Cytori(o) in iugo

loquente saepe sibil(um) edidit coma,

3 Verso raro do ponto de vista da métrica: pausa pentemimere com elisão. Cf. também o v. 8. 
"onde, mais tarde chalupa, antes ela foi

bosque frondoso: tanto que, no cume do Citoro, muitas vezes sibilou, com a fronde sussurrante":

Amástris e o Citoro estão, também, no passado remoto, embora existam ainda.

2) Tibi e cognitissima são o primeiro e o último termo do verso 14: toda a ênfase sobre tibi: de ti, que estás na origem, a origem é mais do que sabida: cognitissima.

3) Finalmente, fuiss(e) et esse: isso está no centro do verso 14 de um poema que tem 27 versos (!): é o cerne do poema.

Muita coisa pode acontecer: pode o pinheiro tornar-se um barco, pode o barco vencer ou não mares e tempestades, pode chegar ou não a um límpido lago, pode envelhecer ou ser destruído: mas aquilo que foi e é a verdade permanece no meio de todos os acidentes: a chalupa é originária do Citoro, e naquele cimo sibilara ao vento.

No verso 15, a expressão ultim(a) ex origine, como eu disse, reforça o antea do verso 10: e o que se segue reporta-se ainda ao passado remoto:

tuo stetisse dicit in cacumine, $t u(o)$ imbuisse palmulas in aequore (v. 16-7),

"que se erguia no teu cimo, que embebia os remos em tuas águas"

com uma elisão altamente sugestiva: $t u(o)$ imbuisse (v. 17): não apenas a chalupa é originária do Ponto mas em suas águas embebia os remos. Os ablativos, iniciando e terminando os versos 16 e 17, dão uma impressão envolvente

tuo [...] in cacumine / tuo [...] in aequore, "no teu cimo / em tuas águas"

com ênfase para o possessivo: tuo, "no teu, do Ponto": não em qualquer outro cimo ou em qualquer outro mar: e sim no Ponto Euxino, origem e razão de sua raça e de seu orgulho. Há algo extraordinário aqui. Está na relação entre o monte e o pinheiro, entre o mar e o barco:

stetisse in cacumine / imbuisse in aequore, "se erguia no teu cimo / embebia em tuas águas" (16-7). 
Enquanto pinheiro, no cimo do monte, ele se erguia acima do monte; enquanto barco, no mar profundo, ele embebia os remos nas águas do mar, numa relação dinâmica, tal como a própria vida. Nestes dois versos quase que se opõem duas concepções de vida ou, melhor, dois momentos de uma vida.

$\mathrm{Na}$ segunda parte (versos 18-21), chamo a atenção para os encadeamentos:

et inde tot per impotentia freta erum tulisse, laeua siue dextera uocaret aura, siue utrumque Iupiter simul secundus incidisset in pedem, "e que daí, por tantos mares tempestuosos, trouxe o seu dono, quer da esquerda ou da direita soprasse a brisa, quer Júpiter ao mesmo tempo lhe houvesse caído, favorável, nas duas escotas"

Nestes versos, o trajeto. Não mais o passado remoto, mas o passado imediato, que constitui a ligação entre a origem e o presente.

Vemos aí a responsabilidade: et inde / erum tulisse (18.19). Inde refere o ponto de partida, o mar Euxino. Vemos a luta com o mar (v. 18); a luta com os ventos, ora caprichosos, batendo a vela (v. 19-20), ora favoráveis, enfunando a vela (v. 21-2). Os encadeamentos destes versos que referem o trajeto (18-21) são, ao meu ver, grandemente sugestivos e, ainda mais sugestiva a aliteração do verso 22: incidisset in pedem, com o vento incidindo, ao mesmo tempo, nas duas escotas.

Esta parte introduz um elemento novo, o dono (erum, v. 19); e mostra como coisa viva, como força dinâmica e arrebatadora, o vento, até então apenas sugerido: em linteo, "vela"(v. 5), ou em sibil(um) edidit, "sibilou"(v. 12, com elisão). Aqui ele levanta os mares (impotentia freta, v. 18), faz oscilar o barco (laeua siue dextera / aura, v. 19-20) ou leva-o a deslizar (Iupiter secundus, v. 20-1).

Terceira parte: versos 22-4:

nequ(e) ulla uota litoralibus Diis

sib(i) esse facta, cum ueniret a marei

nouissim(e) hunc ad usque limpidum lacum,

"e não fez quaisquer votos aos Deuses

litorâneos, embora chegasse do mar,

finalmente, até este límpido lago" 

um barco (Carm. iv). Língua e Literatura, n. 22, p. 137-153, 1996.

Chegada pelas próprias forças. A chalupa não fez quaisquer votos a Deuses. Ela nunca precisou implorar, nunca se viu em situąção tal que implorasse. Nunca encontrou, entre os mares e as tempestades, oponente mais forte que ela, chalupa de pinheiro do Ponto. Preces feitas por ela (sibi, em destaque no verso 23) não houve, embora chegasse até o seu último lar, o lago (v. 24).

Todo este segmento, que compreende estas três partes, do verso 13 ao verso 24, eu o entenderia em dois níveis: primeiro, a chalupa, o cimo do Citoro e o lago: o princípio e o fim; segundo, a chalupa e a sua luta: os adversários, tantos mares e tempestades, e a brisa inconstante; a sua responsabilidade, o dono, que ela trouxe, e o seu valor, Deuses que não precisou invocar.

Quarto e último segmento: versos 25-7:

Sed haec prius fuere: nunc recondita

senet quiete seque dedicat tibi,

gemelle Castor et gemelle Castoris,

"Mas isto foi antes: agora, recolhida, envelhece tranquilamente e se dedica a ti, gêmeo Cástor, a ti, gêmeo de Cástor"

Este é o epílogo: imagem de paz, oposição às lutas: a imagem presente do barco.

O verso 25 encerra a oposição priıı / nunc, "antes / agora"; e resume todas as lutas em um só vocábulo: haec. "isto", e mostra a nova chalupa: recondita, "recolhida": o Poeta marca a tristeza da velhice: phaselus tem, aqui, um predicativo no feminino, recondita: está o barco despojado de sua força.

No verso 26, o advérbio quiete, "tranqüilamente", reforça o predicativo recondita, com o qual se opõe a tudo que pertence ao passado imediato: lutas, ventos e tempestades: haec (v. 25).

Nestes três últimos versos, a chalupa encara a sua nova realidade, expressa pelo advérbio quiete, pelo predicativo recondita, e pelos dois verbos do verso 26: senet e dedicat, "envelhece e se dedica". Entregue à velhice, ela se consagra a Deuses, antes nem lembrados.

Contradição? Impiedade? Piedade tardia? Penso que não. Viril, dedicara-se à luta. Vencedora, consagra-se aos Deuses; e vale notar que estes são romanos.

Em suma, este poema de Catulo tem uma história bem simples. A história de um barco de remos e de vela: sua origem, suas lutas, seu descanso. E há 
algo de muito profundo modificando a simplicidade da história: primeiro, a raça da chalupa: a força de sua origem; segundo, a sua romanização, pois que, originária do Ponto, invoca, ao fim, Deuses romanos.

Poema lírico, encerra toda a magia catuliana. A escolha dos vocábulos, sua posição, suas oposições conseguem toda a força expressiva e intensidade que o Poeta certamente desejou. Por essa força expressiva e intensidade, Catulo transforma a história simples de um barco, que fala e tem memória e, certamente, alma, na história de todos nós.

A visão do passado através do presente mostra perfeito entrosamento entre os três momentos da vida do barco: o passado mais remoto, portanto a origem "primeira" (a última, até onde a memória alcança), o passado imediato, em que viveu vida dinâmica, e o presente, em que, escondida, está entregue aos Deuses. De tal forma estão ligados esses momentos, que cada um explica os outros: tudo o que foi e é prende-se ao que fora e foi.

E coisa curiosa. De tal forma é construída a trama do poema que se pode passar, por exemplo, do $1^{\circ}$ ao $26^{\circ}$ verso, ou do $2^{\circ}$ ao $6^{\circ}$., ou ao $22^{\circ}$., ou ao $25^{\circ}$., ou do $5^{\circ}$. ao $13^{\circ}$., ou ao $22^{\circ}$., ou ao $25^{\circ}$., sem solução de continuidade, isto é, sem problemas, ou sintáticos ou expressivos.

Exemplos:

Phaselus ille, quem uidetis, hospites senet quiete seque dedicat tibi, gemelle Castor et gemelle Castoris;

Phaselus ille, quem uidetis hospites

ait fuisse nauium celerrimus.

Et hoc negat minacis Adriatici negare litus [...];

Phaselus ille, quem uidetis, hospites, ait fuisse nauium celerrimus.

Neque ulla uota litoralibus Diis

sibi esse facta [...];

Phaselus ille, quem uidetis, hospites,

ait fuisse nauium celerrimus.

Sed haec prius fuere; nunc [...];

Phaselus ille, quem uidetis, hospites, 

um barco (Carm. iv). Língua e Literatura, n. 22, p. 137-153, 1996.

neque ullius natantis impetum trabis nequisse praeterire, siue palmulis opus foret uolare siue linteo. Amastri Pontica et Cytore buxifer, tibi haec fuisse et esse cognitissima ait phaselus [...];

Phaselus ille, quem uidetis, hospites, ait fuisse nauium celerrimus, neque ullius natantis impetum trabis nequisse praeterire, siue palmulis opus foret uolare siue linteo. Neque ulla uota litoralibus Diis sibi esse facta, cum veniret a marei [...];

Phaselus ille, quem uidetis, hospites, (v. 1) ait fuisse nauium celerrimus, neque ullius natantis impetum trabis nequisse praeterire, siue palmulis opus foret uolare siue linteo. Sed haec prius fuere; nunc recondita senet quiete seque dedicat tibi, gemelle Castor et gemelle Castoris.

Ao meu ver, este poema, que encerra toda a força da romanidade de Catulo, pleno da arte catuliana, belo na sua aparente simplicidade, musical e azul, é, sem dúvida, uma das obras-primas da literatura latina, para não dizer da literatura ocidental.

\section{BIBLIOGRAFIA}

CATULLE. Poésies. Texte ét. \& trad. par G. Lafaye. Paris, "Les Belles Lettres" 1966.

COSTA, A. Elementos populares em Catulo. São Paulo, Cruzeiro, 1952. Temas clássicos. São Paulo, Cultrix, 1978.

FORDYCE, C. J. Catullus. Oxford, Clarendon, 1973.

GRIMAL, P. L'amour à Rome. Paris, "Les "Belles Lettres", 1979.

NOUGARET, L. Traité de métrique latine classique. Paris, C. Klincksieck, 1963. 

um barco (Carm. iv). Lingua e Literatura, n. 22, p. 137-153, 1996.

QUICHERAT, L. Traité de versification latine. Paris, Hachette, 1870.

VASCONCELOS, P. S. O cancioneiro de Lésbia. São Paulo, Hucitec, 1991. VEYNE, P. A elegia erótica romana. São Paulo, Brasiliense, 1985.

RÉSUMÉ: Catulle, le premier grand poète lyrique latin,poeta nouus selon Cicéron, et héritier de la poésie d'Alexandrie, garde son indépendance vis-à-vis de l'alexandrinisme. Au fait, il semble avoir surpassé les modèles car son génie romain illumine son oeuvre. Donc, le poéme sur le bateau, par exemple, est noveau sous l'art de Catulle, et italien, sans doute. De plus, il révèle la grande technique du Poète et un sentiment dont les couleurs sont marquantes: ce poème, apparemment très simple, a quelque chose de très profond.

Mots-clés: Poésie lyrique, vie, romanité, race. 